\title{
Summer snow extent heralding of the winter North Atlantic Oscillation
}

\author{
Mark A. Saunders, Budong Qian, and Benjamin Lloyd-Hughes \\ Benfield Greig Hazard Research Centre, Department of Space and Climate Physics, University College London, Holmbury \\ St Mary, Dorking, Surrey, UK
}

Received 23 December 2002; revised 3 February 2003; accepted 5 February 2003; published 5 April 2003.

[1] Winter climate over the North Atlantic and European sector is modulated by the North Atlantic Oscillation (NAO). We find that the summer extent of snow cover over northern North America and northern Eurasia is linked significantly $(p<0.01)$ to the upcoming winter NAO state. Summers with high/low snow extent precede winters of low/high NAO index phase. We suggest the linkage arises from the summer snow-associated formation of anomalous longitudinal differences in surface air temperature with the subpolar North Atlantic. Our findings indicate the seasonal predictability of North Atlantic winter climate may be higher and extend to longer leads than thought previously. INDEX TERMS: 3319 Meteorology and Atmospheric Dynamics: General circulation; 3309 Meteorology and Atmospheric Dynamics: Climatology (1620); 4215 Oceanography: General: Climate and interannual variability (3309). Citation: Saunders, M. A., B. Qian, and B. LloydHughes, Summer snow extent heralding of the winter North Atlantic Oscillation, Geophys. Res. Lett., 30(7), 1378, doi:10.1029/ 2002GL016832, 2003.

\section{Introduction}

[2] The North Atlantic Oscillation (NAO) is the dominant mode of boreal winter atmospheric variability over the North Atlantic [Walker and Bliss, 1932; van Loon and Rogers, 1978]. Year-to-year changes in the strength and sign of the winter NAO are linked to interannual variability in wintertime temperature, precipitation and storminess over Europe and the North Atlantic. The correlation between these climate parameters and the 'winter NAO', defined henceforth as $\mathrm{NAO}_{\text {DJF }}$ where DJF is the 3-month winter period December-January-February, reaches $0.7(p<0.001 ; 1950 / 1$ 2001/2) at certain locations [Hurrell, 1995; Marshall et al., 2001]. Skilful NAO seasonal forecasts would bring socioeconomic benefits by forewarning of winter climate anomalies and their impacts on business revenue, commerce and society.

[3] Predictability studies have identified only limited $\mathrm{NAO}_{\text {DJF }}$ skill to date. Efforts have focussed on the role of lagged North Atlantic sea surface temperatures (SSTs). Here we examine the seasonal predictability of the winter NAO from the lagged extent of northern hemisphere $(\mathrm{NH})$ snow cover. We employ the full 30-year record 1972/3-2001/2 of reliable satellite-derived monthly NH snow extents [Robinson et al., 1993]. Recent work has linked autumn (September-October-November) Eurasian snow cover extent to upcoming NH winter climate variability [Cohen and Entekhabi, 1999; Cohen et al., 2001; Saito et al., 2001]. Here we

Copyright 2003 by the American Geophysical Union. 0094-8276/03/2002GL016832 show that it is summer, rather than autumn, snow cover which is related more strongly and robustly to the upcoming $\mathrm{NAO}_{\text {DJF. }}$ The association is strong enough to provide useful long-range NAO predictability with the winter NAO phase being anticipated in up to $80 \%$ of winters. We link the predictability to the summer snow cover-associated formation of anomalous longitudinal gradients in surface air temperature with the subpolar North Atlantic.

\section{Data}

[4] We employ monthly NH ground snow extent records from January 1972 through February 2002. These data are provided by the Snow Data Resource Center at Rutgers University and comprise, after recent processing corrections, the most up-to-date snow cover records currently available. Snow charting improved considerably in 1972 with the satellite deployment of the Very High Resolution Radiometer having a spatial resolution of $1.0 \mathrm{~km}$. Since then the snow extent records are considered reliable for climate analysis studies [Robinson et al., 1993]. We examine the snow cover linkage to three different winter NAO indices to ensure that any association determined has broad application and is not sensitive to the choice of index. The $\mathrm{NAO}_{\mathrm{DJF}}$ indices employed are (a) the standardized difference in mean sea level pressure (MSLP) between southwest Iceland and Gibraltar [Jones et al., 1997] compiled by the Climatic Research Unit at the University of East Anglia; henceforth the CRU NAO $O_{D J F}$ index. (b) the NAO teleconnection index maintained by the US Climate Prediction Center (CPC) and computed from the rotated principal component analysis of monthly northern hemisphere $700 \mathrm{hPa}$ geopotential heights [Barnston and Livezey, 1987]; henceforth the CPC NAO index. (c) the leading principal component of North Atlantic DJF MSLP over the same $\left(20^{\circ} \mathrm{N}-70^{\circ} \mathrm{N}, 90^{\circ} \mathrm{W}-40^{\circ} \mathrm{E}\right)$ sector employed by Hurrell [1995]; henceforth the MSLP NAO $O_{D J F}$ index. The latter is computed using monthly NCEP/NCAR global reanalysis project data [Kalnay et al., 1996] from 1st December 1950 to 28th February 2002. We also employ monthly NCEP/NCAR reanalysis data for $2 \mathrm{~m}$ air temperature to examine the links between snow cover, surface air temperature and gradients in air temperature.

\section{Summer Snow Extent Link to Winter NAO}

[5] Our analysis uses linear detrended time series corrected for autocorrelation throughout. This approach minimises the influence of time series trends and multi-year-to-decadal signal variability on the strength and significance of the computed correlations and the deduced $\mathrm{NAO}_{\mathrm{DJF}}$ predictability. We correct for time series autocorrelation by computing the effective number of degrees of freedom in the crosscorrelation estimation [Davis, 1976] through inclusion of 
(a)

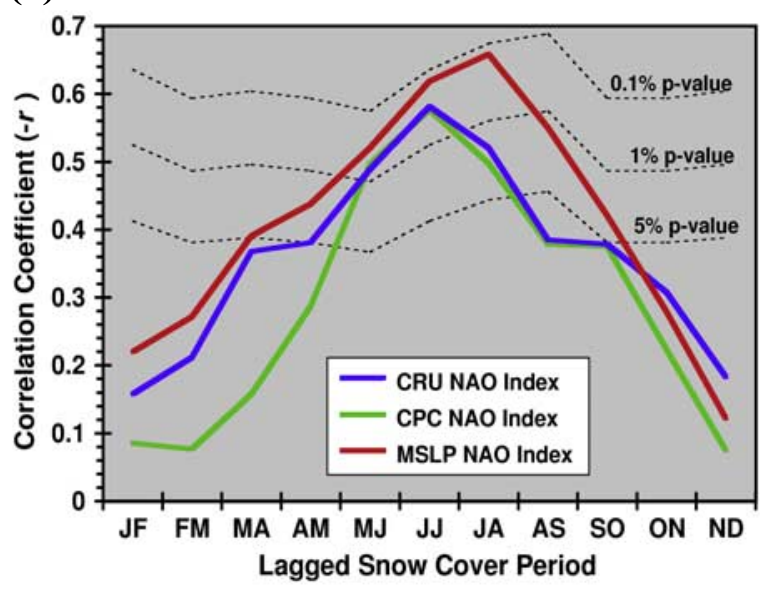

(b)

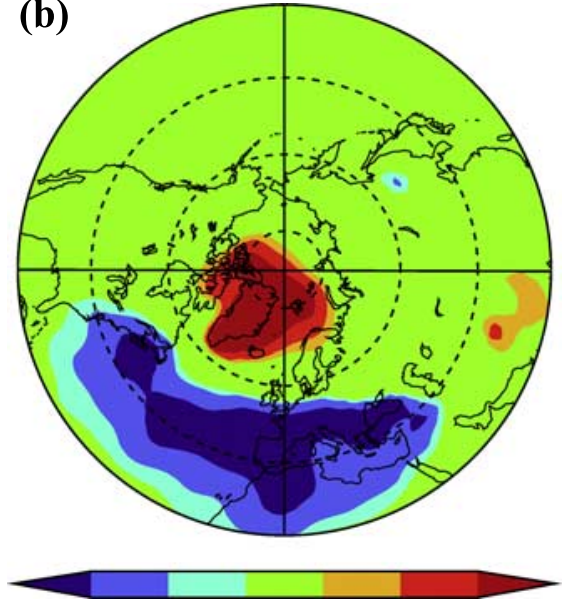

$\begin{array}{llllll}0.01 & 0.05 & 0.10 & 0.10 & 0.05 & 0.01\end{array}$

Figure 1. The link between summer northern hemisphere snow extent and the coming winter NAO 1972/3-2001/2. (a) The correlation between lagged northern hemisphere snow cover and winter $\mathrm{NAO}_{\mathrm{DJF}}$ indices for bi-monthly snow cover periods ranging from JF (January-February) through to ND (November-December). The negative correlations from detrended time series are plotted. Dashed lines display the confidence levels of non-zero correlation between snow extent and the MSLP NAO $O_{D J F}$ index assessed using a 2-tailed Student's $t$-test after correction for autocorrelation with lags out to 15 years included. (b) The correlation pattern significance between detrended time series of June-July northern hemisphere snow extent and the following winter (DJF) northern hemisphere gridded sea level pressure. Significances are corrected for autocorrelation as in (a). Color shading also denotes where the correlation is either positive (orange through red) or negative (light through dark blue).

autocorrelation coefficients in both input time series out to lags of $\mathrm{N} / 2$ years, where $\mathrm{N}$ is the time series length. The use of raw (not detrended) time series corrected for autocorrelation gives, in all cases, links of similar or stronger magnitude and significance to those described herein.

[6] The magnitude, statistical significance and spatial nature of the link between summer $\mathrm{NH}$ snow area of extent and the coming winter NAO are shown in Figure 1 for the period 1972/3-2001/2. Figure 1a displays the negative correlation between time series of lagged bi-monthly $\mathrm{NH}$ snow extents out to 11 months lag and the $C R U, C P C$ and $M S L P \mathrm{NAO}_{\mathrm{DJF}}$ indices. The confidence levels of non-zero correlation between snow extent and the MSLP $\mathrm{NAO}_{\mathrm{DJF}}$ index are shown by the dashed lines; the same confidence levels for the other two NAO indices would, if shown, lie slightly lower on the plot. The significant link between NH snow extent in summer and the coming $\mathrm{NAO}_{\mathrm{DJF}}$ is clear; the correlation $(r)$ magnitude is $>0.57$ and $p$-value $<0.005$ for all June-July NH snow extent to $\mathrm{NAO}_{\mathrm{DJF}}$ index links. The correlation climbs to a significant peak in summer before falling back with the approach of winter. The correlation sign shows that summers with high/low snow extent precede winters of low/high NAO index state. The strength and significance of the summer $\mathrm{NH}$ snow cover association with $\mathrm{NAO}_{\text {DJF }}$ far exceeds that from any other lagged $\mathrm{NH}$ snow cover period. It also exceeds the magnitude and significance of the documented [Cohen and Entekhabi, 1999; Cohen et al., 2001; Saito et al., 2001] autumn Eurasian snow cover to $\mathrm{NAO}_{\text {DJF }}$ link which has a correlation magnitude $<0.35$ and $p$-value $>0.05$ for all NAO indices. Summer Eurasian snow extent and summer North American snow extent are also linked significantly to $\mathrm{NAO}_{\mathrm{DJF}}$. The correlation links for the period 1972/3-2001/2 lie between -0.52 and -0.54 $(p<0.005)$ for June-July Eurasian snow extent to all $\mathrm{NAO}_{\text {DJF }}$ indices, and between -0.54 and $-0.61(p<0.02)$ for June-July North American snow extent to all $\mathrm{NAO}_{\mathrm{DJF}}$ indices. Here 'North American' snow cover excludes Greenland.

[7] The link between summer NH snow extent and the coming winter climate is significant over the North Atlantic and European sector. This is illustrated in Figure $1 \mathrm{~b}$ which shows the correlation pattern significance between winter sea level pressure over the northern hemisphere poleward of $20^{\circ} \mathrm{N}$ and the prior June-July NH snow extent 1972/3$2001 / 2$. Only values significant at levels $<0.10$ are plotted. The pattern is typical of the NAO with $99 \%(100 \%)$ of the northern hemisphere grid cells with correlation significances $<0.05(<0.01)$ being located around the Icelandic low pressure and Azores high pressure regions.

[8] The physical basis for how summer NH snow extent might influence the winter NAO is addressed in Figure 2. Figure 2a displays the correlation pattern significance of June-July NH snow extent against June-July $2 \mathrm{~m}$ surface air temperature 1972/3-2001/2 for the northern hemisphere region poleward of $47.5^{\circ} \mathrm{N}$. The correlation sign and significance are color-coded and displayed for significance levels $<0.10$. Regions of significant negative correlation occur over the Canadian Northwest Territories and the Siberian region adjacent to the Barents and Kara Seas. These regions coincide closely with the location of anomalous June-July snow cover (see the monthly snow cover charts at http://climate.rutgers.edu/snowcover). Thus Figure 2 a shows that summer anomalous snow extent over North America and Eurasia is linked to anomalies (of opposite sign) in the overlying air temperature. The figure also shows a region of significant positive correlation off 
(a)

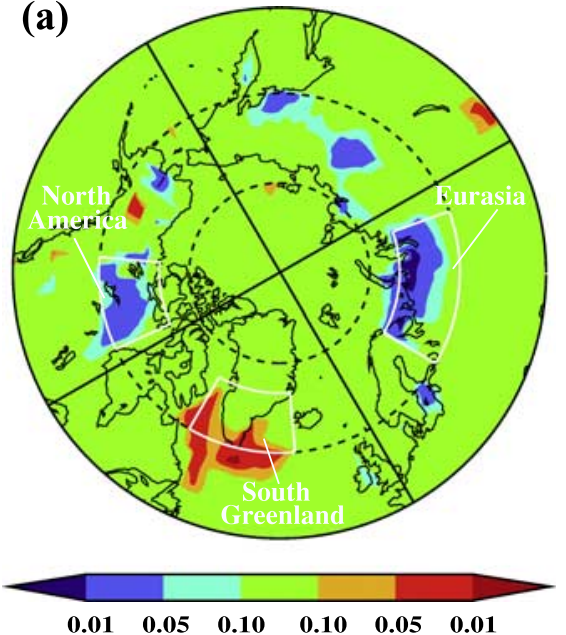

(b)

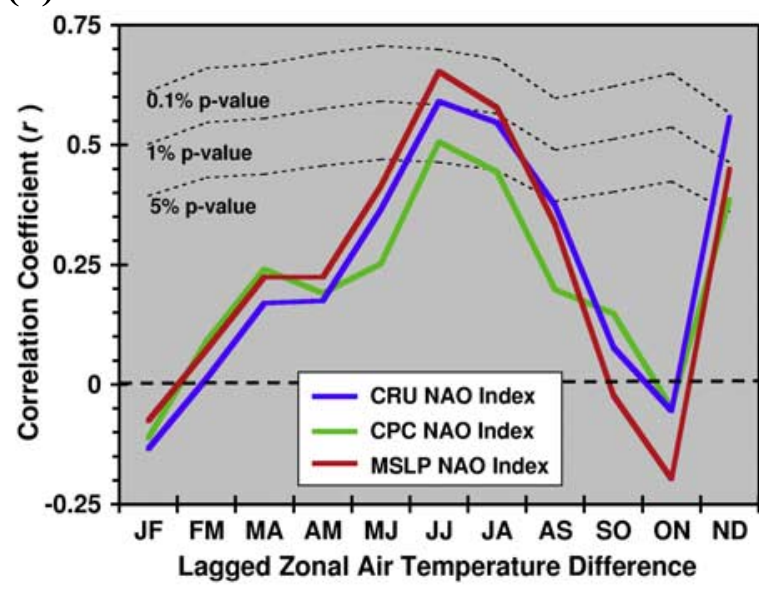

Figure 2. The associations between summer northern hemisphere snow cover, summer subpolar surface air temperature, and the coming winter NAO for the period 1972/3-2001/2. (a) The correlation pattern significance between detrended time series of June-July northern hemisphere snow extent and gridded June-July $2 \mathrm{~m}$ surface air temperature. Significances are corrected for autocorrelation with lags out to 15 years included. Color shading also denotes where the correlation is either positive (orange through red) or negative (light through dark blue). (b) The strength and significance of the correlation between the lagged zonal air temperature difference $\Delta T=($ North America + Eurasia $) / 2-$ South Greenland and coming winter $\mathrm{NAO}_{\mathrm{DJF}}$ indices. The correlations from detrended time series are plotted. Dashed lines display the confidence levels of non-zero correlation between $\triangle T$ and the MSLP NAO $O_{D J F}$ index assessed using a 2-tailed Student's $t$-test after correction for autocorrelation with lags out to 15 years included. The bi-monthly lagged $\Delta T$ intervals range from JF (JanuaryFebruary) through to ND (November-December).

the coast of southern Greenland but this is of secondary importance to the physical mechanism linking snow extent and NAO as described below. Three white boxed sectors are marked on Figure 2a labelled 'North America', 'Eurasia' and 'South Greenland'. These sectors are selected based on the criteria that they best encompass the areas of significant correlation while all lying between $60^{\circ} \mathrm{N}$ and $70^{\circ} \mathrm{N}$. The 'South Greenland' sector, situated between the other two, is also the location of the Icelandic low pressure system in summer. The three sectors are used to define an index of average zonal air temperature difference, $\Delta \mathrm{T}$, between the North America and Eurasia sectors and South Greenland as follows: $\Delta \mathrm{T}=\left(\left(\mathrm{T}_{\text {North America }}-\mathrm{T}_{\text {South Greenland }}\right)+\left(\mathrm{T}_{\text {Eurasia }}-\right.\right.$ $\left.\mathrm{T}_{\text {South Greenland }}\right) / 2$.

[9] The magnitude and statistical significance of the link between lagged $\Delta \mathrm{T}$, computed for $2 \mathrm{~m}$ surface air temperature, and the coming winter NAO is shown in Figure $2 \mathrm{~b}$ for all three $\mathrm{NAO}_{\text {DJF }}$ indices for the period 1972/3-2001/2. The presentation format matches that of Figure 1a. The confidence levels are those of non-zero correlation between snow extent and the MSLP NAODJF index; the same confidence levels for the $C P C$ and $C R U \mathrm{NAO}_{\mathrm{DJF}}$ indices would, if shown, lie lower on the plot because the links to these indices are more significant than indicated in Figure $2 \mathrm{~b}$. The significance and strength of the link between June-July $\Delta \mathrm{T}$ and $\mathrm{NAO}_{\mathrm{DJF}}$ is clear; for all three $\mathrm{NAO}$ indices the link has a $p$-value $<0.01$ and a correlation magnitude $>0.51$. The correlation climbs to a significant peak in summer before falling back with the approach of winter, thus mirroring the findings in Figure 1a. The significant correlation rebound in November-December (ND) reflects the onset of the winter NAO in the South Greenland air temperature. The results of Figure $2 b$ show little sensitivity to extending the data period to 52 years ( $p$-value remains $<0.01$ after correction for autocorrelation for June-July $\Delta \mathrm{T}$ to all winter NAO indices 1950/12001/2), to the choice of $2 \mathrm{~m}$ air temperature data set (we also examined the CRUTEM monthly land air temperature dataset [Jones, 1994]), or to the exclusion of South Greenland in the $\Delta \mathrm{T}$ index calculation (except that the ND peak disappears).

[10] Figure 2 suggests that summer NH snow cover may influence winter NAO predictability through the snow cover-associated formation of anomalous zonal gradients in surface air temperature with the subpolar North Atlantic. These temperature differences would force anomalous meridional thermal winds and, over the North Atlantic, sea level pressure anomalies, a mid-latitude zonal wind anomaly and SST anomalies of the correct sign which, if persisted through to winter, would give the correct winter NAO index sign. This mechanism is consistent with recent observations [Wu and Gordon, 2002; Saunders and Qian, 2002] identifying the EOF 2 mode of North Atlantic SST variability from June to November as correlated significantly and quasi-stably to upcoming winter NAO indices from 1950/1 to present. The EOF 2 pattern is similar to the SST anomaly pattern anticipated above. The magnitude and significance of the link between the June-July NH snow cover time series and the EOF 2 SST principal component time series for August-September-October and September-OctoberNovember 1972-2001 are respectively $r=0.52, p=0.009$ and $r=0.59, p=0.004$. (For raw time series corrected for autocorrelation the values are higher at $r=0.63, p=0.006$ and $r=0.68, p=0.003$ respectively). Thus a significant link exists between summer $\mathrm{NH}$ snow cover and the summer/autumn EOF 2 North Atlantic SST mode, thereby 
Table 1. Hindcast Predictive Skill for the Wintertime MSLP $N A O_{D J F}$ Index from the Prior July-August Northern Hemisphere Snow Extent

\begin{tabular}{ccc}
\hline & Cross-Validated & Replicated Real-Time \\
Skill Measure & $1972 / 3-2001 / 2$ & $1987 / 8-2001 / 2$ \\
\hline$r$ & $0.62(0.61)$ & 0.60 \\
PVE & $38(35)$ & 35 \\
RMSE $_{\text {Clim (Prior 5yr) }}(\%)$ & $34(27)$ & 32 \\
RMSE $_{\text {Clim (1971/2-2001/2) }}(\%)$ & $22(20)$ & 25 \\
MAE $_{\text {Clim (Prior 5yr) }}(\%)$ & $33(25)$ & 23 \\
MAE $_{\text {Clim (1971/2-2001/2) }}(\%)$ & $23(23)$ & 28 \\
\hline
\end{tabular}

Brackets indicate the cross-validated skill with the influence of time series autocorrelation minimized.

enabling a mechanism for coupling between summer and winter.

[11] Although our proposed physical mechanism for explaining the significant link between summer NH snow extent and the upcoming winter NAO is plausible, our analysis can not rule out the existence of another underlying root influence which forces the variability in summer snow cover as well as all associated linking variables. Numerical model experiments with prescribed snow cover conditions will be required to resolve this question.

\section{Prediction Skill for $\mathbf{N A O}_{\mathrm{DJF}}$ Indices}

[12] We assess the seasonal predictability of $\mathrm{NAO}_{\mathrm{DJF}}$ from summer NH snow cover in three ways: from replicated real-time forecasts [Saunders and Qian, 2002] for the recent 15 year period 1987/8-2001/2, from standard cross-validated hindcasts [Michaelsen, 1987] for the full 30 year period 1972/3-2001/2, and from cross-validated hindcasts with the influence of time series autocorrelation minimized for the 24 year period 1975/6-1998/9. In the latter scheme successive 7 years centered on the forecast year are withdrawn and a regression model is built on the remaining 23 years to predict the $\mathrm{NAO}_{\mathrm{DJF}}$ of each withdrawn year. We compute the predictive deterministic skill for $\mathrm{NAO}_{\mathrm{DJF}}$ using four skill measures: the correlation $(r)$ between forecast and observed $\mathrm{NAO}_{\mathrm{DJF}}$ values, the percentage of variance explained (PVE), the percentage improvement in root mean square error over a climatological forecast $\left(\mathrm{RMSE}_{\mathrm{Clim}}\right)$ and the percentage improvement in mean absolute error over a climatological forecast $\left(\mathrm{MAE}_{\mathrm{Clim}}\right)$. Two climatologies are used for the latter skill measures: the standard 30-year 1971/ $2-2000 / 1$ fixed climate norm and a running prior 5-year climate norm. The latter minimizes skill inflation caused by decadal trends in $\mathrm{NAO}_{\mathrm{DJF}}$. Table 1 displays the predictive skill for the MSLP NAO DJF index from July-August NH snow cover. It shows that irrespective of hindcast model and skill measure, the wintertime NAO is predictable from $\mathrm{NH}$ summer snow extent with a correlation skill of $\sim 0.6$, with $35 \%$ of its variance being explained and with a skill improvement over climatology of $20-35 \%$. The model also anticipates the correct MSLP NAO $(75 \%)$ of the 30 standard (24 autocorrelation-corrected) cross-validated forecast winters and in $93 \%$ of the 15 replicated real-time forecast winters.

\section{Conclusions}

[13] We find that summer snow cover over northern North America and northern Eurasia is linked significantly to the coming winter NAO state. These results are based on 30 years of reliable snow cover records. A longer data series would provide greater confidence in the temporal stability of this link. However, using summer air temperature as a proxy for snow cover we find for the extended 52 year period 1950/1-2001/2 that the summer $\Delta \mathrm{T}$ link to all winter NAO indices remains significant to $p<0.01$ after correction for autocorrelation. Our finding suggests that the seasonal predictability of North Atlantic winter climate may be higher and extend to longer leads than thought previously. It also suggests that summer NH snow extent may be relevant for longer term forced shifts in climate.

[14] Acknowledgments. This work is supported by the United Kingdom Natural Environment Research Council. We thank R. T. Sutton, D. A. Robinson and two anonymous reviewers for helpful comments on the manuscript. We acknowledge the Snow Data Resource Center at Rutgers University for snow extent records (http://climate.rutgers.edu/snowcover) and NOAA-CIRES, Climate Diagnostics Center, Boulder, Colorado for NCEP/NCAR Global Reanalysis Project Data.

\section{References}

Barnston, A. G., and R. E. Livezey, Classification, seasonality and persistence of low-frequency atmospheric circulation patterns, Mon. Weather Rev., 115, 1083-1126, 1987.

Cohen, J., and D. Entekhabi, Eurasian snow cover variability and Northern Hemisphere climate predictability, Geophys. Res. Lett., 26, 345-348, 1999.

Cohen, J., K. Saito, and D. Entekhabi, The role of the Siberian high in the Northern Hemisphere climate variability, Geophys. Res. Lett., 28, 299302, 2001.

Davis, R. E., Predictability of sea surface temperature and sea level pressure anomalies over the North Pacific Ocean, J. Phys. Oceanog., 6, 249-266, 1976.

Hurrell, J. W., Decadal trends in the North Atlantic Oscillation: Regional temperature and precipitation, Science, 269, 676-679, 1995.

Jones, P. D., Hemispheric surface air temperature variations: A reanalysis and an update to 1993, J. Climate, 7, 1794-1802, 1994.

Jones, P. D., T. Jónsson, and D. Wheeler, Extension to the North Atlantic Oscillation using early instrumental pressure observations from Gibraltar and South-West Iceland, J. Climate, 17, 1433-1450, 1997.

Kalnay, E., et al., NCEP/NCAR 40-year reanalysis project, Bull. Am. Meteorol. Soc., 77, 437-471, 1996.

Marshall, J., et al., North Atlantic climate variability: phenomena, impacts and mechanisms, Int. J. Climatol., 21, 1863-1898, 2001.

Michaelsen, J., Cross-validation in statistical climate forecast models, J. Clim. Appl. Meteorol., 26, 1589-1600, 1987.

Robinson, D. A., K. F. Dewey, and R. R. Heim Jr., Global snow cover monitoring: An update, Bull. Am. Meteorol. Soc., 74, 1689-1696, 1993.

Saito, K., J. Cohen, and D. Entekhabi, Evolution of atmospheric response to early-season Eurasian snow cover anomalies, Mon. Weather Rev., 129, 2746-2760, 2001.

Saunders, M. A., and B. Qian, Seasonal predictability of the winter NAO from North Atlantic sea surface temperatures, Geophys. Res. Lett., 29(22), 2049, doi:10.1029/2002GL014952, 2002.

van Loon, H., and J. C. Rogers, The seesaw in winter temperatures between Greenland and northern Europe, Part I, General description, Mon. Weather Rev., 106, 296-310, 1978.

Walker, G. T., and E. W. Bliss, World Weather V, Mem. R. Meteorol. Soc., 4, 53-84, 1932.

Wu, P., and C. Gordon, Oceanic influence on North Atlantic climate variability, J. Clim., 15, 1911-1925, 2002.

B. Lloyd-Hughes, B. Qian, and M. A. Saunders, Department of Space and Climate Physics, University College London, Holmbury St. Mary, Dorking Surrey, RH5 6NT, UK. (mas@mssl.ucl.ac.uk) 